\title{
A Novel Resident and Medical Student Curriculum in Refugee Health
}

\author{
Susan Levine, $M D M P H^{\top} \oplus$ and Mohaned Serdah, $B S^{2}$ \\ 'UConn Health, Farmington, CT, USA; ${ }^{2}$ University of Connecticut School of Medicine, Farmington, CT, USA.
}

$\mathrm{J}$ Gen Intern Med 35(7):2237-9

DOI: $10.1007 / \mathrm{s} 11606-020-05693-6$

(c) Society of General Internal Medicine 2020

\section{INTRODUCTION}

Approximately $1 / 3$ of the 70 million globally displaced are refugees. ${ }^{1}$ Refugees have unique health care needs including recognition and treatment of chronic conditions related to their country of origin, or specific to their migration pattern. Significant knowledge gaps potentially exist between physicians and their ability to treat refugees. ${ }^{2}$ Caring for immigrants offers a unique opportunity to develop global health and cross-cultural communication skills and to explore complex determinants of health. Training in cultural competency and health care disparities is required by the LCME and ACGME ${ }^{3-5}$ To address these curricular needs at the University of Connecticut, a novel resident and medical student curriculum was developed.

\section{METHODS}

Resident Curriculum. Residents attend a 2-h introductory lecture after which they can enroll in a voluntary 6-month elective. Upon enrollment, residents receive a thumb drive of 69 core references group by 15 content areas to which they can refer throughout and after the elective. The elective includes monthly interactive meetings. Residents are assigned 5-6 readings per session from the reference list. They review

This work has not been previously published and represents the sole work of the authors. Preliminary information on the curricular content has been briefly presented in poster form at the New England regional SGIM meeting on 11/2/19 and at the Global Health Symposium of Connecticut Childrens Medical Center on May 30, 2018.

Received December 14, 2019

Accepted January 31, 2020

Published online February 19, 2020 assigned readings beforehand. Meetings take place after "business" hours and last approximately $3 \mathrm{~h}$. Topics covered include but are not limited to cultural sensitivity, domestic screening, immunizations, endemic disease unique to refugees, chronic disease, women's health, mental health, and asylum issues. Throughout the sessions, residents apply their learning to immigrant patients they encounter in their own continuity clinics and then share these experiences with the group at the beginning of each session. To date, 28 residents have completed the 6-month elective. Residents complete an 88 -question pre- and post-curricular assessment.

Medical Student Curriculum. Students attend a 1-week immersion experience. A smaller subset of the resident curricular materials is posted on line with 2-3 readings from this subset assigned per session. The in-class content for the medical student elective is adapted from the resident curriculum and adjusted to fit the student learner level. Day 1 covers an introduction to the current state of the global refugee crisis. Students learn the difference between refugees and asylees and gain an understanding of the resettlement process. On day 2 , students practice techniques to explore cultural determinants of health. Day 3 reviews some of the unique requirements of the domestic screening exam. On day 4, students explore chronic and infectious diseases unique to refugees. On day 5 , the course concludes with a look at mental health issues unique to refugees, the challenges facing asylum seekers as well as forensic advocacy work. To date, 20 medical students have completed the 1-week elective. Students complete a 33question pre- and post-curricular assessment.

Statistical Analyses. Individual assessment scores, cohort means, total means, individual question means, and topic category means for pre- and post-curricular assessments were calculated. Summary statistics of the scores of the medical students and the residents were compiled. A paired Student $t$ test was used to compare the pretest and posttest mean scores of the medical students and the mean scores of the residents. 


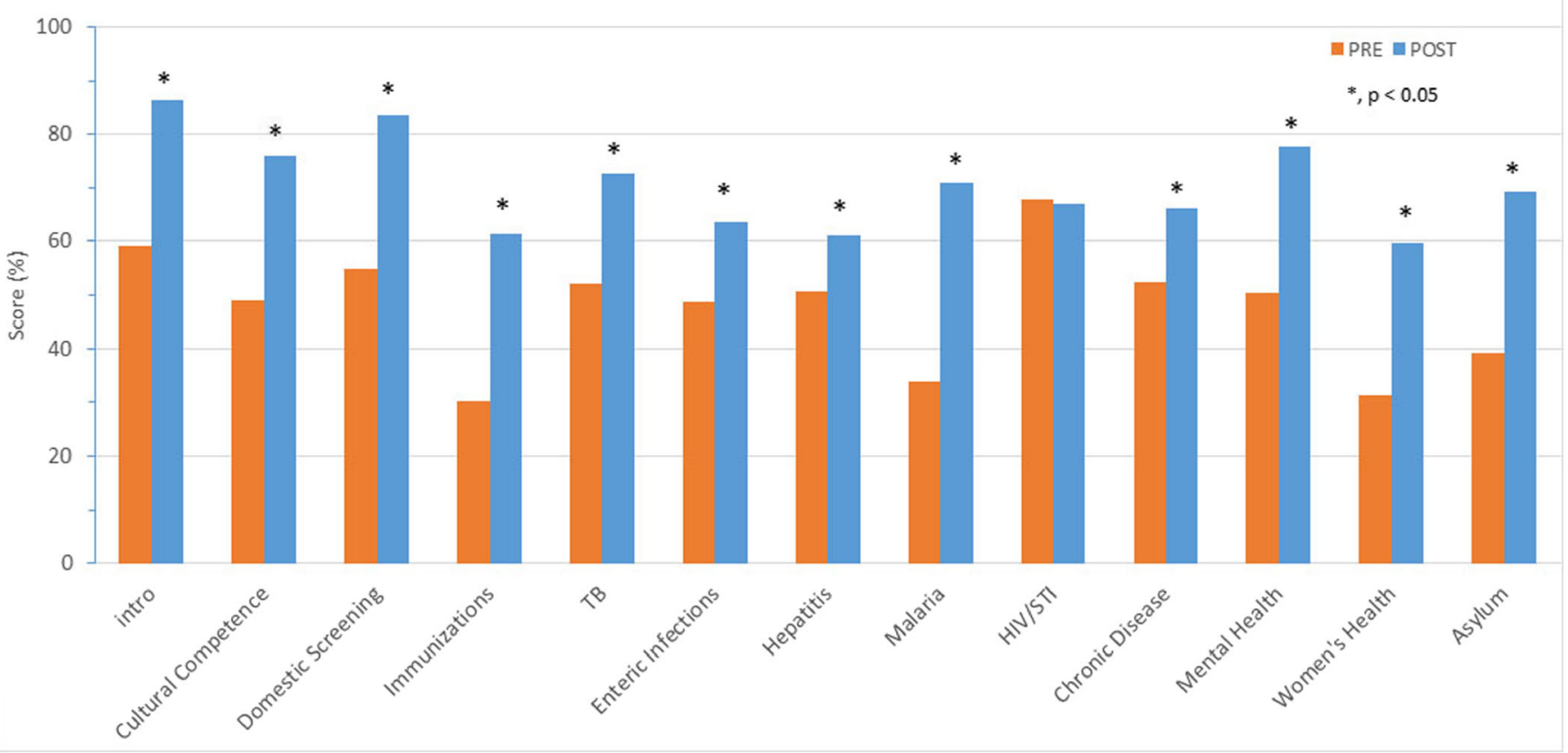

Fig. 1 Resident curricular scores by question category. TB tuberculosis, STI sexually transmitted infections, HIV human immune deficiency virus.

Statistical significance was defined as a two-tailed $p$ value of $<0.05$.

\section{RESULTS}

Resident Data. A $50 \%$ increase in overall curricular knowledge scores was seen at 6 months. Knowledge in all content areas except HIV increased. Knowledge about malaria, immunizations, asylum, and women's health increased by more than $75 \%$. Increases of $25-50 \%$ were seen in the remaining content areas (Fig. 1).] $\rightarrow$

Medical Student Data. A $74 \%$ increase in the overall curricular knowledge scores was demonstrated in the medical student curriculum. Knowledge in all content areas except chronic disease increased by $50 \%$ or more. The number of questions in each content area and the number of content areas were smaller compared with the resident assessment (Fig. 2).] $\rightarrow$

\section{DISCUSSION}

Most resident and medical student scores increased significantly. Flat and high baseline resident scores in HIV may reflect prior familiarity. Flat student scores in chronic disease likely reflect a smaller number of questions in this category. Introduction pre-curricular scores were higher for students and included fewer questions relative to other categories. The curriculum offers a unique opportunity to explore the power of advocacy and teaches residents and students skills in crosscultural medicine that are transferrable to the care of a wide range of patients.

Acknowledgments: I would like to acknowledge Dr. Aniyizhai Annamalai, director of Yale's adult refugee clinic for her ongoing mentorship, and the many medical residents and students who participated in the curriculum for their valuable feedback.

Corresponding Author: Susan Levine, MD MPH; UConn Health, Farmington, CT, USA (e-mail: slevine@uchc.edu).

\section{Compliance with Ethical Standards:}

Conflict of Interest: There are no conflicts of interest or funding to report. 


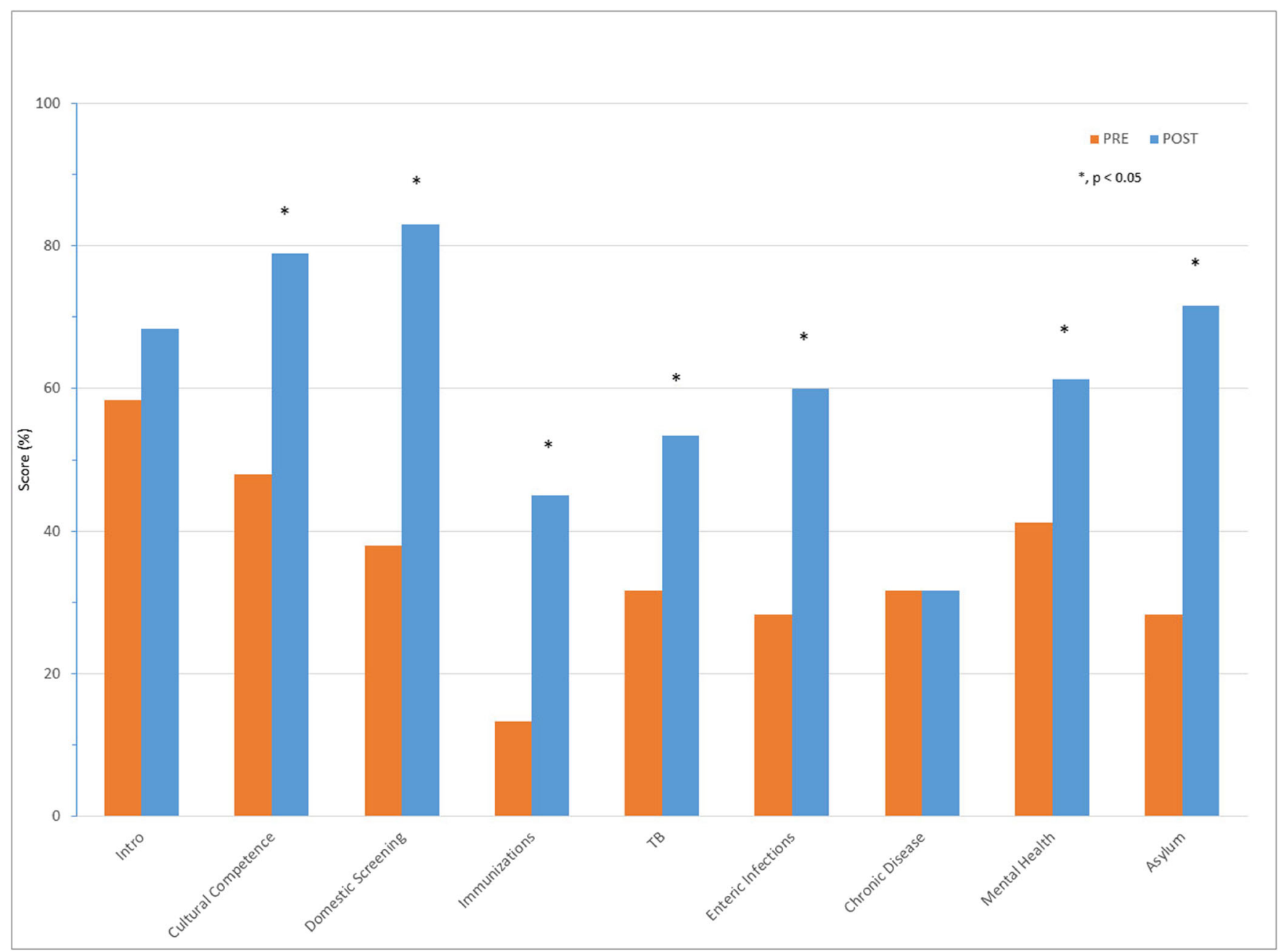

Fig. 2 Student refugee curricular scores by question category. TB tuberculosis.

\section{REFERENCES}

1. Global Trends. Forced Displacement in 2017. United Nations High Commissioner for Refugees. Available at: https://www.unhcr.org/en-us/ statistics/unhcrstats/5b27be547/unhcr-global-trends-2017.html. Accessed 8 Dec 2019.

2. Morris MD, Popper ST, Rodwell TC, Brodine SK, Brouwer KC. Healthcare Barriers of Refugees Post-resettlement. J Community Health 2009;34(6):529-538

3. Maldaado, Maria et al. The Role that Graduate Medical Education Must Play in Ensuring Health Equity and Eliminating Health Care Disparities, Ann Am Thorac Soc . 2014; 11(4):603-07.
4. Accreditation Council for Graduate Medical Education, February 2017, Clinical Learning Environment Review, Issue Brief No. 4: Health Care Disparities. Available at: https://www.acgme.org/Portals/0/PDFs/CLER/ CLER_Health_Care_Disparities_Issue_Brief.pdf.

5. US Department of Health and Human Services. Cultural Competence in Medical Education: a Guidebook for Schools. Available at: https://www. hrsa.gov/sites/default/files/culturalcompetence/cultcomp.pdf. Accessed 8 December 2019.

Publisher's Note Springer Nature remains neutral with regard to jurisdictional claims in published maps and institutional affiliations. 